\title{
Sleep quality in survivors of critical illness: practical shortcomings resolved
}

\author{
M. Bolaki ${ }^{1} \cdot$ Ch. Alexopoulou ${ }^{2,3} \cdot$ D. Georgopoulos ${ }^{2,3}$ \\ Received: 28 August 2018 / Accepted: 6 September 2018 / Published online: 17 September 2018 \\ (C) Springer Nature Switzerland AG 2018
}

Keywords Critical illness $\cdot$ ICU discharge $\cdot$ Sleep quality $\cdot$ Sleep-disordered breathing $\cdot$ ARDS

\begin{abstract}
Abbreviations
ICU Intensive care unit

ARDS Acute respiratory distress syndrome

SDB Sleep-disordered breathing
\end{abstract}

\section{To the Editor}

We would like to thank El-Khatib and Esquinas for their valuable comments regarding our paper [2] and for giving us the opportunity to clarify some important issues.

We agree with El-Khatib and Esquinas that the effect of critical illness on sleep may be underestimated since the patients were studied several days/weeks after intensive care unit (ICU) discharge [2]. Obviously, sleep at ICU discharge should be severely influenced by abnormalities in gas exchange (almost all patients need supplementary oxygen for some time after ICU discharge) and other ICU-related factors, making both the performance and interpretation of sleep studies problematic. Nevertheless, the main aim of our study was to investigate sleep quality in ICU survivors with normal or near normal blood gases. Our study clearly showed that this patient population suffers from significant sleep disruption and sleep-

This reply refers to the letter available at https://doi.org/10.1007/s11325018-1719-2.

D. Georgopoulos georgopd@uoc.gr

1 Department of Pulmonary Medicine, University Hospital of Heraklion, Medical School, University of Crete, Heraklion, Greece

2 Intensive Care Medicine Department, University Hospital of Heraklion, Medical School, University of Crete, Heraklion, Greece

3 Sleep Laboratory, Intensive Care Medicine Department, University Hospital of Heraklion, Medical School, University of Crete, Heraklion, Greece disordered breathing (SDB) of obstructive type, which improved slightly at 6 months [2]. We believe that these results point out that these patients need close follow-up and, possibly, diagnostic sleep procedures, both at hospital discharge and at least 6 months later.

The design of our study does not permit the identification of pathophysiologic mechanisms [3] which underline the observed SDB. We hope that our study will pave the way for future studies to further explore the mechanisms of SDB in this specific population of ICU survivors. In addition, the number of patients with acute respiratory distress syndrome (ARDS) was relatively small, making the relationships between variables related to ARDS characteristics and management and sleep quality questionable. Moreover, few patients were classified as having severe ARDS (seven patients) and as a result the use of neuromuscular blocking agents and prone position was applied in a small number of patients (six and one patient respectively). This small number of patients precludes a meaningful statistical analysis. We certainly agree with El-Khatib and Esquinas that both the severity of ARDS and management strategies may affect our results. We also agree that intubation-related factors, by affecting either the genioglossus muscle or the passive properties of upper airways (i.e., mechanical damage), may influence our results [4]. However, to confirm the contribution of these factors to SDB, we must specifically examine the function of genioglossus muscle and upper airways' passive properties in all patients during sleep. This was not the aim of our study.

The issue of patient-ventilator dys-synchrony deserves some comments. Firstly, in this patient population, patientventilator dys-synchrony was not studied and, therefore, we cannot further comment on that issue. Nevertheless, the effect of patient-ventilator dys-synchrony on sleep during critical illness is controversial [5]. Secondly, we have shown that patient-ventilator dys-synchrony is not a constant phenomenon but tends to occur in clusters, making the identification of 
dys-synchrony very demanding [6]. This necessitates special equipment [6] and thus, different study design.

\section{Compliance with ethical standards}

Conflict of interest The authors declare that they have no conflict of interest.

\section{References}

1. El-Khatib MF, Esquinas AM (2018) Sleep quality in survivors of critical illness: practical shortcomings unresolved. Sleep Breath https://doi.org/10.1007/s11325-018-1719-2

2. Alexopoulou C, Bolaki M, Akoumianaki E, Erimaki S, Kondili E, Mitsias P, Georgopoulos D (2018) Sleep quality in survivors of critical illness. Sleep Breath. https://doi.org/10.1007/s11325-0181701-z

3. Wellman A, Edwards BA, Sands SA, Owens RL, Nemati S, Butles J, Passaglia CL, Jackson AC, Malhotra A, White DP (2013) A simplified method for determining phenotypic traits in patients with obstructive sleep apnea. J Appl Physiol 114:911-922

4. Shah AC, Barnes C, Spiekerman CF, Bollag LA (2015) Hypoglossal nerve palsy after airway management for general anesthesia: an analysis of 69 patients. Anesth Analg 120(1):105-120

5. Alexopoulou C, Kondili E, Plataki M, Georgopoulos D (2013) Patient-ventilator synchrony and sleep quality with proportional assist and pressure support ventilation. Intensive Care Med 39:10401047

6. Vaporidi K, Lilitsis E, Kondili E, Amargianitakis V, Chouvarda I, Maglaveras N, Georgopoulos D (2017) Clusters of ineffective efforts during mechanical ventilation: impact on outcome. Intensive Care Med 43(2):184-191 